\title{
Comparative analysis of enzymatic activity of tannase in non-conventional yeasts to produce ellagic acid
}

\author{
Anahí Márquez-López ${ }^{1}$ Juan David Ramírez-Conejo², Ma. Del Carmen Chávez-Parga ${ }^{1}$, \\ Dora Cecilia Valencia Flores ${ }^{2}$, Miguel Angel Zamudio Jaramillo², \\ Horacio González Rodríguez ${ }^{1}$, Juan Carlos González-Hernández ${ }^{2 \star}$ (iD
}

\begin{abstract}
Non-conventional yeasts represent an alternative for microorganisms that are capable to produce the enzyme Tannase (EC 3.1.1.20), which has many applications is the food and pharmaceutical industry as it stands out for its ability to produce ellagic acid out of the enzymatic hydrolysis of ellagitannins. Ellagic acid has been studied in the medical area for its action against various diseases, as is the case of cancer or heart problems. The investigation was conducted to evaluate seven non-conventional yeasts - Debaryomyces hansenii PYC ISA 1510, Debaryomyces hansenii PYC 2968, Candida parapsilosis, Candida utilis, Pichia pastoris, Pichia kluyveri, Issatchenkia terricola - as producers of the enzyme tannase. This was done in mediums of fermentation with tannic acid (1-3\%) and YPD without tannic acid, to determine the activity of the enzyme by two spectrophotometric methods, the first being with rhodamine and the second with methyl gallate, to detect the presence of gallic acid as a product of the hydrolysis of tannic acid. The main results showed that the evaluated non-conventional yeasts all presented activity with the Tannase enzyme, obtaining better detection results with the rhodamine technique for the stability of the formed complex, which gives more precision of the obtained data.
\end{abstract}

Keywords: non-conventional yeasts; enzymatic activity; tannase; ellagic acid; hydrolysis.

Practical Application: The spectrophotometric determination of strains of non-conventional yeasts capable of producing enzyme tannase allow their use in new biotechnological processes.

\section{Introduction}

Ellagic acid is a polyphenolic compound obtained by the degradation of ellagitannins present in various fruits and plants, which has a lot of applications in various areas such as nutraceutical, pharmaceutical, cosmetic and food industry (Vázquez-Flores et al., 2012). A large amount of research has been carried out to produce ellagic acid where three main factors have been considered, degrading enzymes of ellagitannins such as tannase (EC 3.1.1.20) and $\beta$-glucosidase (EC 3.2.1.21), filamentous fungi of the genus Aspergillus that are the principal producing organisms of these enzymes, and different vegetal sources rich in ellagitannins. The use of fungi entails an increase in the amount of substrate required for their growth and a longer time for fermentation, which in turn has an impact on the energy costs. For these disadvantages, the investigation is developing alternatives to improve said process, using non-conventional yeasts as microorganisms that produce the enzymes of interest, reducing fermentation time, costs of maintenance and adaptation of microorganisms.

The investigations that have been carried out on the production of tannase in yeasts are very scarce. Aoki et al. (1976) began reporting the production, purification and characterization of the enzyme tanasa of a Candida yeast sp. K-1. Albertse (2002) managed to express the tannase gene from $A$. oryzae in a strain of Saccharomyces cerevisiae. Zhong et al. (2004) cloned and expressed the tannase gene from A. oryzae in the yeast Pichia pastoris, and Shi et al. (2005) found tannase activity in the C. utilis strain. This investigation seeks to expand the information about the production of tannase in non-conventional yeast strains that have not been reported in the literature, pointing out that these strains have not been genetically modified.

The yeasts that are detected with the highest enzymatic activity, will be used to produce ellagic acid by means of a fermentation process. Using the enzymatic function of hydrolysis of the tannase, on the ester bonds that bind the hexahydroxydiphenic acid molecules (HHDP) with the glucose molecule, to then undergo a spontaneous lactonization of the HHDP molecule, the product of interest is obtained. Tannase is known as an enzyme that hydrolyses the tannic acid ester to give gallic acid and glucose. In the presence of tannase, the ester linkages between the HHDP and glucose groups that make up the ellagitannins in strawberry and blackberry should be broken. The non-conventional yeasts are an option to produce ellagic acid through the enzymatic activity for tannase. In the present investigation, presence of said activity has been analysed in the following microorganisms: Debaryomyces hansenii PYC ISA 1510, Debaryomyces hansenii

${ }^{1}$ Posgrado de la Facultad de Ingeniería Química, Universidad Michoacana de San Nicolás de Hidalgo, Morelia, Michoacán. México

${ }^{2}$ Tecnológico Nacional de México, Instituto Tecnológico de Morelia, Morelia, Michoacán. México

*Corresponding author: jcgonzal@itmorelia.edu.mx 
PYC 2968, Candida parapsilosis, Candida utilis, Pichia pastoris, Pichia kluyveri, Issatchenkia terricola.

\section{Materials and methods}

\subsection{Strains of non-conventional yeasts}

Twenty-one strains of non-conventional yeasts were analysed, of which seven strains were selected. Two of the non-conventional yeast strains, which are D. hansenii PYC 2968 and D. hansenii PYC ISA 1510 come from the Higher Institute of Agronomy in Lisbon, Portugal. The strains C. utilis, C. parapsilosis, P. kluyvery, I. terricola and P. pastoris are maintained and conserved in the strain collection of the Biochemistry Laboratory of the Tecnológico de Morelia. The selection was made based on the screening described below.

\subsection{Screening of non-conventional yeast strains}

The yeasts strains were inoculated in a medium containing $5 \mathrm{~g} \mathrm{~L}^{-1}\left(\mathrm{NH}_{4}\right)_{2} \mathrm{SO}_{4}, 0.5 \mathrm{~g} \mathrm{~L}^{-1} \mathrm{MgSO}_{4} .7 \mathrm{H}_{2} \mathrm{O}, 1 \mathrm{~g} \mathrm{~L}^{-1} \mathrm{~K}_{2} \mathrm{HPO}_{4}$, $1 \mathrm{~g} \mathrm{~L}^{-1} \mathrm{KH}_{2} \mathrm{PO}_{4}, 0.02 \mathrm{CaCl}_{2} .2 \mathrm{H}_{2} \mathrm{O}, 20 \mathrm{~g} \mathrm{~L}^{-1}$ glucose, $10 \mathrm{~g} \mathrm{~L}^{-1}$ casein peptone, $10 \mathrm{~g} \mathrm{~L}^{-1}$ yeast extract, $30 \mathrm{~g} \mathrm{~L}^{-1}$ agar, sterilized in a Felisa autoclave model FE-398 at $121^{\circ} \mathrm{C}$ for 15 minutes. The strains underwent successive adaptation with tannic acid concentrations of 1 to $3 \%(\mathrm{w} / \mathrm{v})$. As a control a medium without tannic acid was used. After 24 hours in the KITlab incubator model EK- 36 at $30^{\circ} \mathrm{C}$ the strains that grew in all the concentrations were selected.

\subsection{Culture conditions and yeast growth}

The selected strains were inoculated in liquid culture medium, $5 \mathrm{~g} \mathrm{~L}^{-1}\left(\mathrm{NH}_{4}\right)_{2} \mathrm{SO}_{4}, 0.5 \mathrm{~g} \mathrm{~L}^{-1}$ of $\mathrm{MgSO}_{4} .7 \mathrm{H}_{2} \mathrm{O}, 1 \mathrm{~g} \mathrm{~L}^{-1}$ of $\mathrm{K}_{2} \mathrm{HPO}_{4}, 1 \mathrm{~g} \mathrm{~L}^{-1} \mathrm{KH}_{2} \mathrm{PO}_{4}, 0.02$ of $\mathrm{CaCl}_{2} .2 \mathrm{H}_{2} \mathrm{O}, 20 \mathrm{~g} \mathrm{~L}^{-1}$ glucose, $10 \mathrm{~g} \mathrm{~L}^{-1}$ of casein peptone, $10 \mathrm{~g} \mathrm{~L}^{-1}$ of yeast extract, $1-3 \%(\mathrm{w} / \mathrm{v})$ of tannic acid, with initial cell concentration of $3 \times 10^{6}$. Afterwards they remained for 24 hours in the Shaker SI-300R at $180 \mathrm{rpm}$ at $30^{\circ} \mathrm{C}$. The sampling time was taken every 4 hours. As a control a medium without tannic acid was used.

\subsection{Cellular concentration}

The cell concentration was determined by a direct count in Neubauer's camera using $100 \mu \mathrm{L}$ of the fermentation medium and $1 \%$ methylene blue for staining the cells. The technique of González-Hernández et al. (2015), was taken and modified. With this cellular count, the lag growth phase was determined, exponential and stationary. With the equation $\mathrm{dN} / \mathrm{dt}=\mu \mathrm{N}$ the integral was obtained: $\mathrm{Ln}$ (number of cells / $\mathrm{mL}$ ) - Ln (number of initial cells $/ \mathrm{mL}$ ) $=\mu \mathrm{t}$. When graphing the $\mathrm{Ln}$ of the number of cells versus the time, $\mu$ is the slope in the graph. The lag phase and the stationary phase have a slope of zero. The lag phase is for the adaptation of the cells and is very short. The stationary phase takes longer, there is no increase in the number of cells and it is when the most metabolic reactions take place.

\section{$2.5 \mathrm{pH}$}

The taken and modified technique of González-Hernández et al. (2015), indicates that a sample of $1.5 \mathrm{~mL}$ must be taken every 4 hours during the 32 hours of development of the fermentation kinetics, by means of a Hanna Instruments ${ }^{\circledR}$ potentiometer the hydrogen potential was measured.

\subsection{Sugar reducers}

Using Miller's technique (Miller, 1959), the consumption of sugar reducers was analysed in the four different media: $0 \%, 1 \%, 2 \%$, and $3 \%$ of tannic acid. An aliquot of $1 \mathrm{~mL}$ was taken and centrifuged. Of the supernatant $10 \mu \mathrm{L}$ was taken and mixed with 3,5-dinitrosalicylic acid (DNS). The reaction was carried out at $100{ }^{\circ} \mathrm{C}$ in a water bath and then taken to an ice bath. The solution was measured in Perkin Elmer Lambda ${ }^{\circledR}$ 35 spectrophotometer at $540 \mathrm{~nm}$.

\subsection{Quantification of the protein}

The production of extracellular protein was analysed by the Bradford technique (Bradford, 1976). $50 \mu \mathrm{L}$ of the supernatant obtained by centrifugation of the fermented medium was taken to react with the Bradford reagent and was quantified in the Perkin Elmer Lambda ${ }^{\circledR} 35$ spectrophotometer at $595 \mathrm{~nm}$.

\subsection{Determination of enzymatic activity of tannase}

The enzymatic activity of tannase has been determined by two methods. For the first determination, a modification was made to the method described by Sharma et al. (2000).

$50 \mu \mathrm{L}$ of enzymatic extract was mixed with $250 \mu \mathrm{L}$ of citrate buffer $50 \mathrm{mM}(\mathrm{pH} 5,0)$ and $450 \mu \mathrm{L}$ of methyl gallate substrate $10 \mathrm{mM}$ (Sigma Aldrich) dissolved in citrate buffer $50 \mathrm{mM}$ (pH 5.0). The mixtures were incubated in a Felisa digital thermobath for 5 minutes at $30^{\circ} \mathrm{C}$. After incubation, $300 \mu \mathrm{L}$ of rhodamine (2-thioxo-4-thiazolidione, Sigma Aldrich) was added at a concentration of $0.667 \%$ and then incubated for 5 minutes at $30^{\circ} \mathrm{C}$. A solution of $200 \mu \mathrm{L}$ of $0.5 \mathrm{~N} \mathrm{KOH}$ was added and the mixture was incubated for a further 5 minutes at $30^{\circ} \mathrm{C}$. At last the mixture was diluted with $4 \mathrm{~mL}$ of distilled water. The reading was performed on the Perkin Elmer Lamba spectrophotometer 35 at $520 \mathrm{~nm}$.

The second method was taken and modified from the methodology described by Nishitani \& Osawa (2003). $50 \mu \mathrm{L}$ of the enzymatic extract was mixed with $450 \mu \mathrm{L}$ of phosphate buffer $40 \mathrm{mM}(\mathrm{pH} 5,0)$ and $500 \mu \mathrm{L}$ of a solution that contains methyl gallate $50 \mathrm{mM}$ (Sigma Aldrich) in phosphate buffer. The mixtures were incubated at $37^{\circ} \mathrm{C}$ for 24 hours, then $1000 \mu \mathrm{L}$ of saturated sodium bicarbonate solution was added. The absorbance was read at $450 \mathrm{~nm}$ by an Epoch $^{\circledR}$ microplate spectrophotometer

\section{Results and discussion}

\subsection{Growth kinetics}

The objective of the growth kinetics is to determine the characteristic growth phases of the yeasts. In Figure 1, the growth kinetics of D. hansenii PYC ISA 1510 are shown, in part a) the cell growth of the YPD medium that was used as a control is shown, observing the start of the stationary phase at hour 8 , the same as with the media; b) $1 \%$; c) $2 \%$ and d) $3 \%$, respectively. There can be seen that the adaptation phase of the microorganism is lower in the concentration of $0 \%$ or control 
and of $1 \%$ of inducer lasting 2 hours, while for $2 \%$ and $3 \%$ of inducer the adaptation phase prolongs up to 4 hours.

One can notice that when increasing the inductor concentration, the cellular concentration decreases. This was seen in the rest of the yeasts, for which the doubling time $\left(t_{D}\right)$ and the specific growth rate $(\mu)$ were evaluated. In Table 1 the behaviour of yeast

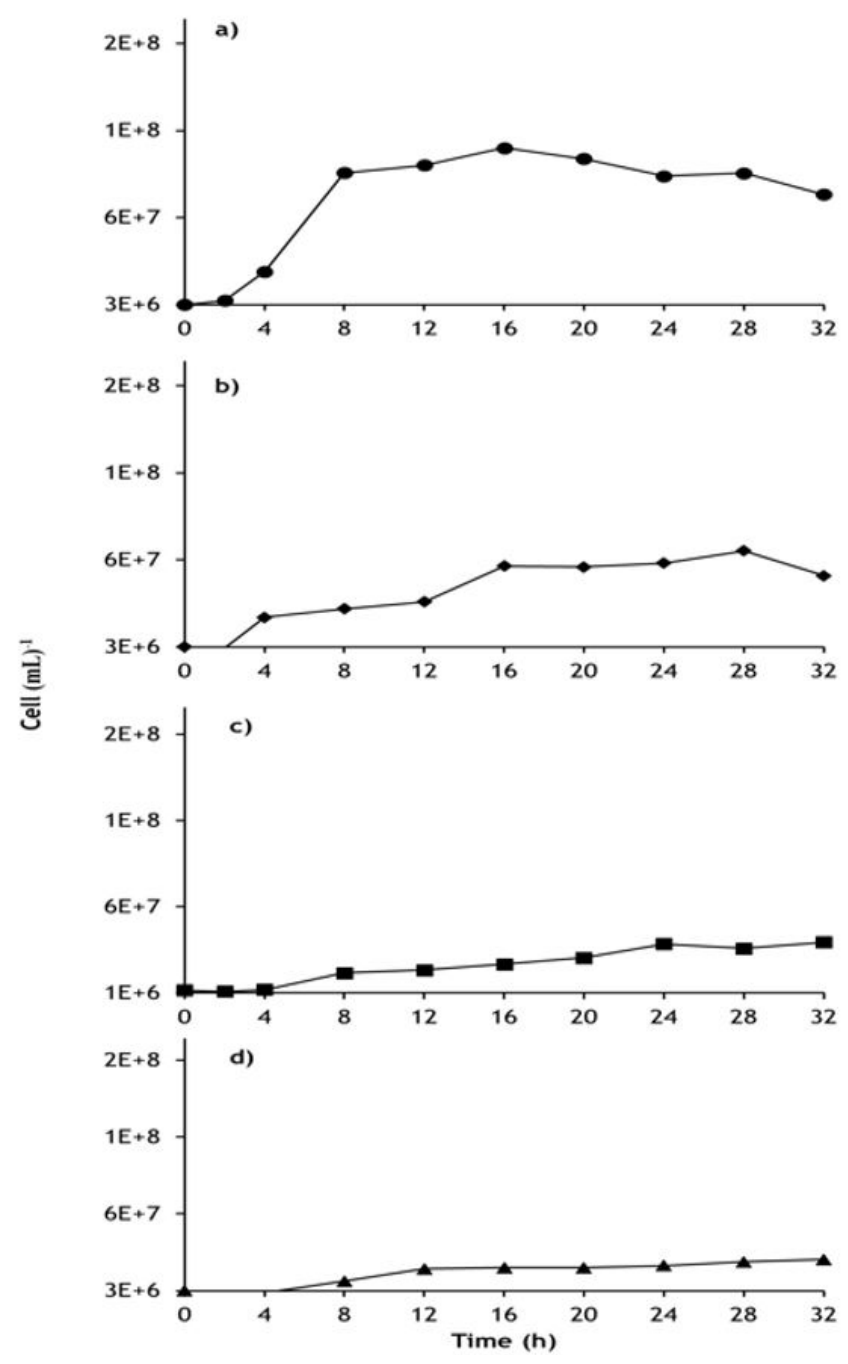

Figure 1. Cellular growth kinetics of D. hansenii PYC ISA 1510, a) YPD control $(\bullet)$, b) $1 \%$ of tannic acid ( $\bullet)$, c) 2\% of tannic acid (•), d) $3 \%$ of tannic acid $(\boldsymbol{\Delta})$. in liquid media with tannic acid has been shown in a comparative way with respect to the control.

The growth kinetics show a typical behaviour of strains of yeasts where we can highlight the determination of the stationary phase, whose importance at this point is that during the exponential phase the enzymes are produced in small quantities and accumulate in this phase. There was a decrease of cellular concentration while the concentration of tannic acid increased, however, these dates are found within the reported values for non-conventional yeast like Candida shehatae, Candida guilliermondii and Saccharomyces kluyvery, with average growth rates of $0.32 \pm 0.01 \mathrm{~h}^{-1}, 0.30 \pm 0.07 \mathrm{~h}^{-1}$ and $0.19 \pm 0.02 \mathrm{~h}^{-1}$, respectively, (González-Hernández et al., 2015).

As can be seen the average growth rate decreases while the concentration of tannic acid increases for D. hansenii PYC 2968, C. utilis, C. parapsilosis and P. kluyvery. In the case of I. terricola and P. pastoris the difference decreases between the concentrations of tannic acid and the YPD control. For D. hansenii PYC ISA 1510, there is no significant difference between the concentrations evaluated, which gives an indication that the substrate was better metabolized. The parameter that give us the information as an indicator of the yeast metabolism, being used to check the effect, whether positive or negative, of a substrate on the microorganisms is the time of duplication. For the strains, D. hansenii PYC 2968, C. utilis, C. parapsilosis, the duplication time was growing as the concentration of tannic acid increased, being a positive effect of it on the metabolism of the microorganism. The time of duplication for P. kluyvery and $I$. terricola decreases when increasing the concentration of tannic acid, indicative that the yeast metabolism has a positive effect to process the tannic acid. D. hansenii PYC ISA 1510 and $P$. pastoris are yeasts that do not present difference in the values of the time of duplication with respect to the control, indicating that their metabolism is processing the molecules of tannic acid with greater normality than the other strains of yeast.

\section{$3.2 p H$}

The variation of the extracellular $\mathrm{pH}$, corresponding to each one of the non-conventional yeast in the YPD medium are shown in Figure 2a. In Figure 2b, the results of the extracellular pH quantified in D. hansenii PYC 2968 are shown, with the three inductor concentrations and the control. There can be seen that the tannic acid influenced the initial $\mathrm{pH}$ of each medium, decreasing according to the increase of this concentration. In addition, the mechanism of acidification of the medium was carried out in the

Table 1. Duplication time $\left(t_{\mathrm{D}}\right)$ and specific growth rate $(\mu)$ of the yeasts in YPD medium and media with tannic acid concentrations (1\% -3\%). The data is presented as the mean \pm standard deviation, $n=2$.

\begin{tabular}{|c|c|c|c|c|c|c|c|c|}
\hline \multirow{2}{*}{ Yeast } & \multicolumn{2}{|c|}{ YPD } & \multicolumn{2}{|c|}{ Tannic acid (1\%) } & \multicolumn{2}{|c|}{ Tannic acid (2\%) } & \multicolumn{2}{|c|}{ Tannic acid (3\%) } \\
\hline & $\mu\left(\mathrm{h}^{-1}\right)$ & $t_{D}(h)$ & $\mu\left(h^{-1}\right)$ & $t_{D}(h)$ & $\mu\left(h^{-1}\right)$ & $t_{D}(h)$ & $\mu\left(h^{-1}\right)$ & $t_{D}(h)$ \\
\hline D. hansenii PYC 2968 & $0.30 \pm 0.07$ & $1.64 \pm 0.11$ & $0.28 \pm 0.06$ & $1.72 \pm 0.10$ & $0.26 \pm 0.08$ & $1.98 \pm 0.10$ & $0.21 \pm 0.05$ & $2.33 \pm 0.14$ \\
\hline C. utilis & $0.30 \pm 0.09$ & $1.68 \pm 0.05$ & $0.22 \pm 0.07$ & $2.31 \pm 0.14$ & $0.20 \pm 0.08$ & $2.80 \pm 0.41$ & $0.21 \pm 0.08$ & $2.74 \pm 0.41$ \\
\hline C.parapsilosis & $0.23 \pm 0.05$ & $2.07 \pm 0.18$ & $0.21 \pm 0.02$ & $2.27 \pm 0.44$ & $0.21 \pm 0.02$ & $2.28 \pm 0.50$ & $0.14 \pm 0.03$ & $3.53 \pm 0.18$ \\
\hline P. kluyvery & $0.21 \pm 0.00$ & $2.38 \pm 0.68$ & $0.17 \pm 0.02$ & $1.77 \pm 0.18$ & $0.15 \pm 0.02$ & $2.03 \pm 0.30$ & $0.12 \pm 0.01$ & $2.08 \pm 0.55$ \\
\hline I. terricola & $0.24 \pm 0.00$ & $2.09 \pm 0.57$ & $0.26 \pm 0.04$ & $1.20 \pm 0.16$ & $0.25 \pm 0.06$ & $1.36 \pm 0.33$ & $0.24 \pm 0.09$ & $1.74 \pm 0.64$ \\
\hline P. pastoris & $0.26 \pm 0.08$ & $1.98 \pm 0.06$ & $0.24 \pm 0.06$ & $2.01 \pm 0.09$ & $0.28 \pm 0.08$ & $1.79 \pm 0.01$ & $0.25 \pm 0.05$ & $1.89 \pm 0.17$ \\
\hline D. hansenii PYC ISA 1510 & $0.16 \pm 0.02$ & $3.07 \pm 0.50$ & $0.16 \pm 0.00$ & $1.85 \pm 0.04$ & $0.15 \pm 0.00$ & $1.95 \pm 0.00$ & $0.15 \pm 0.00$ & $2.03 \pm 0.04$ \\
\hline
\end{tabular}


same way as without inductor, for which it is ruled out that it has a secondary effect on the plasma membrane. This tendency was also found in the six remaining yeasts.

During the process of the lag phase it continues to be constant, as it moves towards the exponential phase it decreases, it becomes constant again in the stationary phase. The decrease of the $\mathrm{pH}$ in the exponential phase is related to the activity of the ATPase of the protons of the plasma membrane, which participates in the regulation of the average internal $\mathrm{pH}$ by pumping protons to the outside of the cells (González-Hernández et al., 2015).

The $\mathrm{pH}$ range in which the medium is found for the four different concentrations is the optimum for tannase, since it has been reported that its maximum activity occurs at acid $\mathrm{pH}$ values (4.3-6.5) (Ramírez-Coronel et al., 2003). Barthomeuf et al. (1994), determined that the $\mathrm{pH}$ with values lower than 3.5 the enzyme is unstable, while at values above 5.0 the hydrolysis of the substrate and the diffusion of the enzyme in the medium is carried out. Making a comparison with the dates of $\mathrm{pH}$ that were obtained in this investigation, where the acidification of the fermentation was maintained above a $\mathrm{pH}$ of 5.0, to consider the possibility that the tannase enzyme that was determined in this investigation was extracellular. However, this is not a decisive parameter that permits this to be an overwhelming conclusion. So that this term is only used as an indicative, which could help to explain its spectrophotometric determination without requiring a cellular breakdown.

\subsection{Sugar reducers}

The consumption of the sugar reducers was carried out in the expected manner in the YPD media and with a concentration of $1 \%$ of tannic acid for all the yeasts, however, a different behaviour for $2 \%$ of tannic acid for the yeast D. hansenii ISA 1510 was observed, which is shown in Figure $3 \mathrm{a}$, where until the $20^{\text {th }}$ hour a progressive consumption is shown. In the case of the fermentation mediums with $3 \%$ of inducer, there can be seen in Figure $3 b$, for C. utilis and Figure 3a for D. hansenii ISA 1510, that there does not exist a significant decrease in the existing glucose in the medium, beginning to observe almost constant values that fluctuate near the $15 \mathrm{~g} / \mathrm{L}$.

The same behaviour was observed with C. parapsilosis where the kinetics with $1 \%$ and $2 \%$ had a similar behaviour to the control (medium with YPD) (Figure not shown), while the kinetic with $3 \%$ if the acid kept swinging around the $15 \mathrm{~g} / \mathrm{L}$. In the case of P. pastoris, P. kluyveri, and I. terricola no significant differences between the mediums of fermentation that were compared have been found. For D. hansenii PYC 2968 the consume was more stable and like the control in comparison to the rest of the kinetics.

The behaviour of the consumption of reducing sugars is attributed to the general reaction of hydrolysis of tannase on the tannic acid molecule, in which it gives as a new product gallic acid molecules and a glucose molecule for each substrate molecule, which may explain why the amount of sugars in the medium does not decrease in fermentations with higher concentration of inducer in the kinetics of D. hansenii ISA 1510, C. utilis and C. parapsilosis

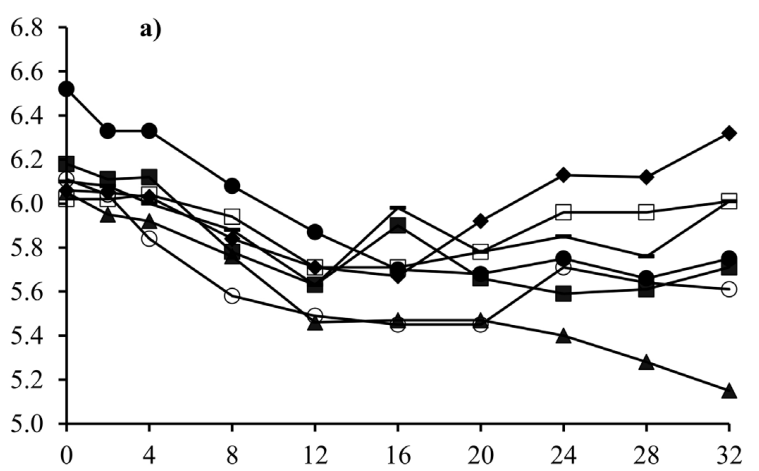

풀

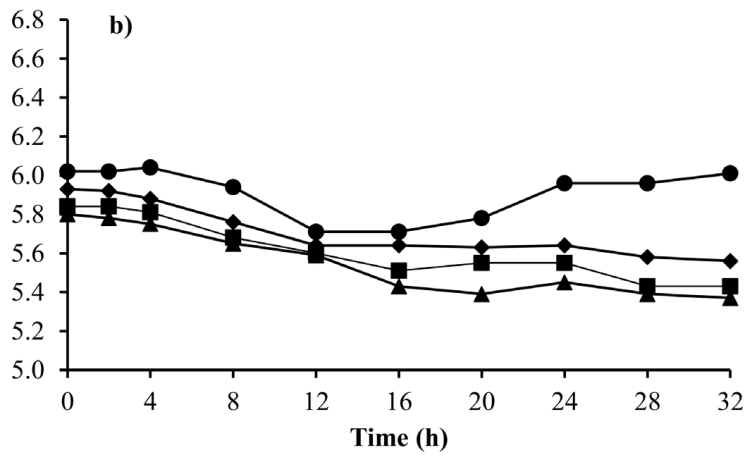

Figure 2. Changes of $\mathrm{pH}$ during fermentation, a) Medium YPD, P. pastoris ( $\square$ ), D. hansenii PYC 2968 (०), D. hansenii PYC ISA 1510 (-), C. utilis ( $\mathbf{\Delta}$ ), P. kluyveri $(\bullet)$, I. terrícola $(\bullet)$, C. parapsilosis ( $\bullet$ ). b) D. hansenii PYC 2968, YPD control (•), b) $1 \%$ of tannic acid $(\bullet)$, c) $2 \%$ of tannic acid (•), d) 3\% of tannic acid ( $\mathbf{\Delta})$.

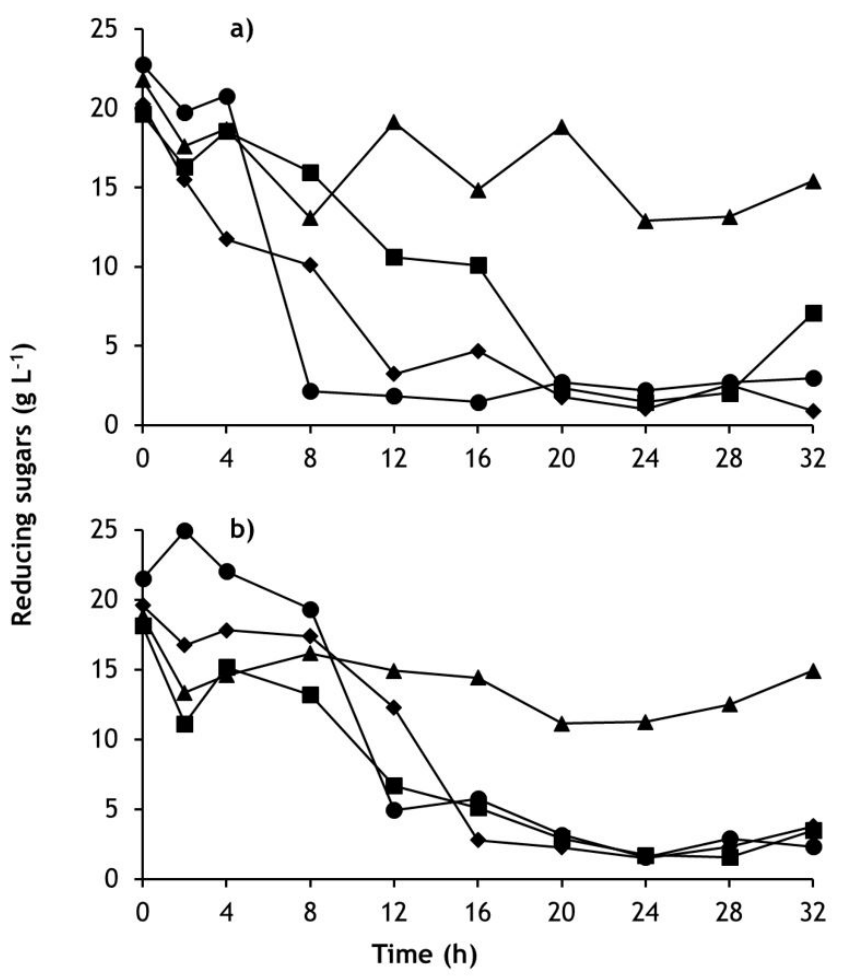

Figure 3. Consumption of reducing sugars of the strains: a) $\mathbf{D}$. hansenii PYC ISA 1510; b) C. utilis, YPD control (•), 1\% of tannic acid ( $\bullet)$, $2 \%$ of tannic acid (-), $3 \%$ of tannic acid $(\boldsymbol{\Delta})$. 


\subsection{Enzymatic activity}

In the nineties, the production of the enzyme tannase was mainly attributed to the fungal species, from the year 2000 studies were started showing that the production of the enzyme was also carried out by bacteria and yeasts. In the same way it was determined that, depending on the microorganism and the fermentation conditions, it is inducible or constitutive. The mechanics of induction and repression are not clear and there is some controversy about the role played by some compounds in their regulation (Aguilar et al., 2001a, 2001b). However, Doi et al. (1973), Beverini \& Metche (1990), reported that tannase is an inducible enzyme and Lekha \& Lonsane (1994), Chatterjee et al. (1996) reported that it was extracellular. For this investigation, given that the mediums with $0 \%$ of tannic acid concentrations presented zero enzymatic activity, the indication is given that for non-conventional yeasts the enzymatic production of Tannase are inducible, as the enzymes are not being continuously expressed without the induced conditions in the medium. Furthermore, it can be considered as a positive induction as the substrate triggers the synthesis of enzymes, unleashing this reaction through the inductor. The inducible systems correspond to enzymatic methods that degrade a compound. In comparison, a repressor carries out a negative induction, where the final product of the reaction that catalyses the enzyme prevents a synthesis, corresponding these systems to metabolic routes.

As can be seen in Figure 4, for P. pastoris, (a) using the methyl gallate technique, and (b) with the rhodamine technique, that when increasing the presence of tannic acid in the medium, the expression of the enzyme amplifies, being null in the mediums with YPD.

There can be seen that this tendency maintains in both methods, increasing the enzymatic activity while increasing the concentration of the inducer, however, the methyl gallate technique gives minor enzymatic activity values. This may be due to the stability of the technique with respect to rhodamine. During this investigation with the rhodamine methodology, enzymatic activity began around $2 \mathrm{~h}$ of fermentation. As the concentration of tannic acid increased in the medium the activity also increased. The highest values were presented in the strain $P$. pastoris, with 0.4934 at $32 \mathrm{~h}, 0.6987$ at $24 \mathrm{~h}$ and 1.57 at $12 \mathrm{~h} \mu \mathrm{mol}$ (min mg of protein) $)^{-1}$ for $1 \%, 2 \%$ and $3 \%$ of tannic acid respectively. After which the values of $D$. hansenii ISA 1510 were presented with the maximum activity at 12 hours of fermentation with $3 \%$ of inducer, presenting $1.1354 \mu \mathrm{mol}$ (min $\mathrm{mg}$ of protein) $)^{-1}$, followed by $0.9829 \mu \mathrm{mol} / \mathrm{min}$ mg of protein at 16 hours with $2 \%$ inducer, and finally 0.3559 $\mu \mathrm{mol}$ (min mg of protein) ${ }^{-1}$ with $1 \%$ tannic acid. For C. parapsilosis values of $1.2596 \mu \mathrm{mol}$ (min mg of protein) ${ }^{-1}$ were obtained with 12 hours of fermentation with 3\% of tannic acid, after 32 hours of fermentation with $2 \%$ of inducer, $0.7662 \mu \mathrm{mol} / \mathrm{min} \mathrm{mg}$ of protein was obtained. The maximum enzymatic activity values presented by D. hansenii PYC 2968 for $1 \%, 2 \%$ and 3\% of tannic acid were $0.3342,0.7100$ and $1.0528 \mu \mathrm{mol} / \mathrm{min} \mathrm{mg}$ of protein, respectively with 24 hours of fermentation for the 3 cases. C. utilis obtained, 0.5848 and $0.2780 \mu \mathrm{mol}$ (min $\mathrm{mg}$ of protein $)^{-1}$, for the media with $1 \%, 2 \%$ and $3 \%$, respectively with 28 hours

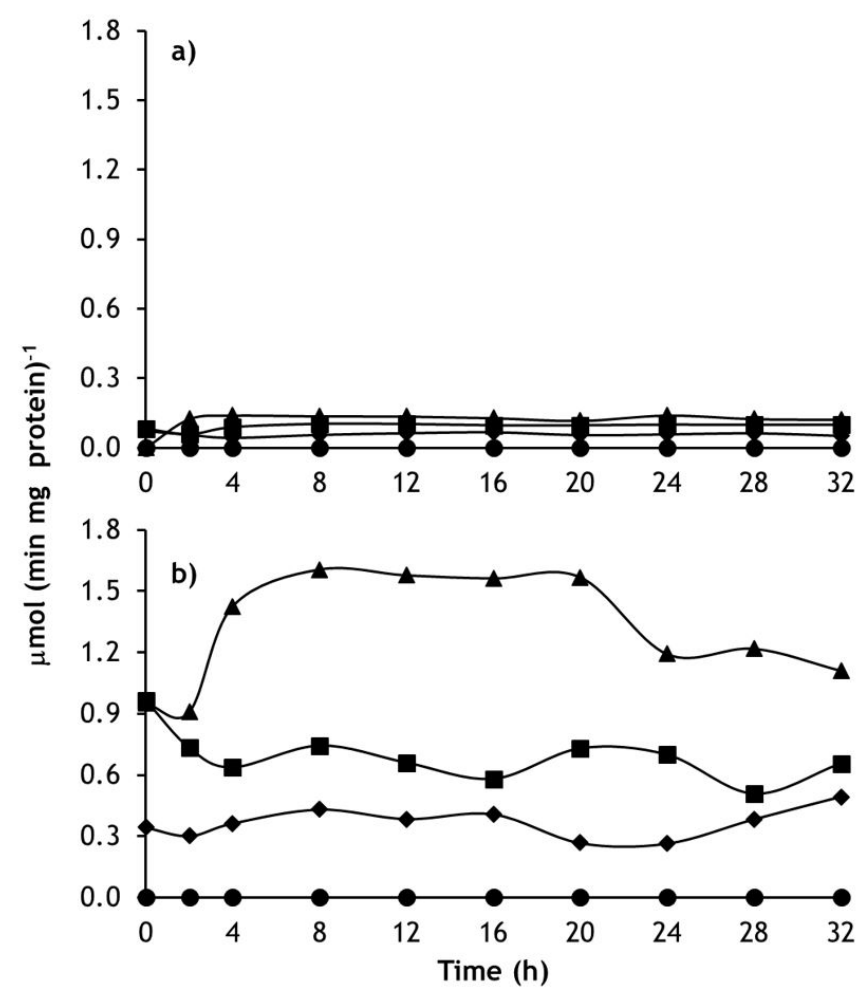

Figure 4. Enzyme activity of tannase for yeast $P$. pastoris, a) Methyl gallate method; b) Rhodamine. YPD control (•), $1 \%$ of tannic acid ( $\bullet$ ), $2 \%$ of tannic acid $(-), 3 \%$ of tannic acid $(\boldsymbol{\Delta})$.

of fermentation. P. kluyvery with 28 hours of fermentation, for kinetics with $1 \%, 2 \%$ and $3 \%$ of inducer, $0.9220,0.9330$ and 0.9805 $\mu \mathrm{mol}$ (min mg of protein) ${ }^{-1}$ respectively. Finally, were the values obtained using I. terricola with $0.8251 \mu \mathrm{mol}$ (min $\mathrm{mg}$ of protein $)^{-1}$ with $1 \%$ inducer with 28 hours of fermentation, 0.6142 $\mu \mathrm{mol}$ (min mg of protein) $)^{-1}$ with $2 \%$ acid with 28 hours, and $0.7559 \mu \mathrm{mol}$ (min mg of protein) $)^{-1}$ with $3 \%$ inducer and 32 hours of fermentation.

In Table 2 a summary of the results of the enzymatic activity of obtained Tannase is presented with the seven non-conventional yeasts in the mediums with 1,2 , and $3 \%$ of tannic acid. The results are expressed as the average of the ten measurements that were realized at the lengths of the 32 hours that took the kinetics to obtain the standard deviation, which indicates how scattered the data are in respect to the mean. The higher the standard deviation is, the greater the scattering of the data will be. There can be seen that the determined activity with methyl gallate is less in comparison with the results obtained with rhodamine. In general, it is seen that in both methods an increase in the enzymatic activity exists when increasing the concentration of tannic acid. This is more evident between $2 \%$ to $3 \%$ of acid in the medium with D. hansenii PYC 2968, D hansenii PYC ISA1510, C. parapsilosis and $P$. pastoris standing out. It is important to note that the results of the control with YPD or concentrations with $0 \%$ of tannic acid where omitted, since there were seen negative enzymatic activities, indicating that the enzymatic activity was zero. 
Table 2. Enzyme activity of tannase expressed in $\mu \mathrm{mol} / \mathrm{min} \mathrm{mg}$ protein, in YPD medium with tannic acid concentrations (1\%-3\%), expressed for two spectrophotometric methods: methyl gallate and rhodamine. The data is presented as the mean \pm standard deviation, $\mathrm{n}=10$.

\begin{tabular}{|c|c|c|c|c|}
\hline \multirow{3}{*}{$\begin{array}{l}\text { Spectrophotometric } \\
\text { methods }\end{array}$} & \multirow{3}{*}{ Yeast } & \multicolumn{3}{|c|}{ Enzyme activity of tannase ( $\mu \mathrm{mol} / \mathrm{min} \mathrm{mg}$ protein $)$} \\
\hline & & \multicolumn{3}{|c|}{ Concentration of tannic acid } \\
\hline & & $1 \%$ & $2 \%$ & $3 \%$ \\
\hline \multirow{4}{*}{ Methyl Gallate } & D. hansenii PYC 2968 & $0.0756 \pm 0.0105$ & $0.1281 \pm 0.0284$ & $0.1705 \pm 0.0380$ \\
\hline & C. parapsilosis & $0.0533 \pm 0.0267$ & $0.1208 \pm 0.0281$ & $0.1606 \pm 0.0372$ \\
\hline & P. kluyvery & $0.07451 \pm 0.0080$ & $0.0604 \pm 0.0078$ & $0.0521 \pm 0.0092$ \\
\hline & D. hansenii PYC ISA 1510 & $0.0766 \pm 0.0087$ & $0.1186 \pm 0.0143$ & $0.1681 \pm 0.0224$ \\
\hline \multirow{6}{*}{ Rhodamine } & \multirow{3}{*}{ Yeast } & \multicolumn{3}{|c|}{ Enzyme activity of tannase $(\mu \mathrm{mol} / \mathrm{min} \mathrm{mg}$ protein $)$} \\
\hline & & \multicolumn{3}{|c|}{ Concentration of tannic acid } \\
\hline & & $1 \%$ & $2 \%$ & $3 \%$ \\
\hline & D. hansenii PYC 2968 & $0.2613 \pm 0.0580$ & $0.5832 \pm 0.1223$ & $1.0085 \pm 0.1422$ \\
\hline & P. pastoris & $0.3642 \pm 0.0725$ & $0.6911 \pm 0.1211$ & $1.3124 \pm 0.2967$ \\
\hline & D. hansenii PYC ISA 1510 & $0.2836 \pm 0.0811$ & $0.8365 \pm 0.1151$ & $1.1521 \pm 0.0978$ \\
\hline
\end{tabular}

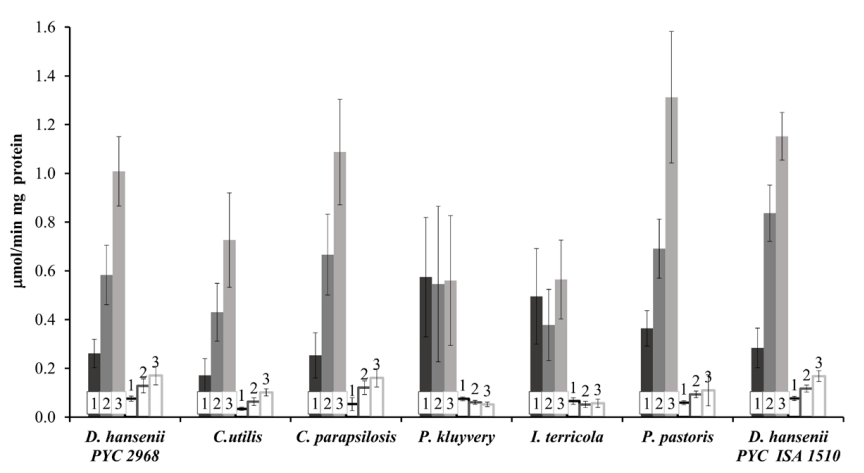

Figure 5. Enzyme activity of tannase determined with: a) Rhodamine: $1 \%$ of tannic acid (1), $2 \%$ of tannic acid (2), 3\% of tannic acid (3); b) Methyl gallate: $1 \%$ of tannic acid (1), $2 \%$ of tannic acid (2), $3 \%$ of tannic acid (3). Comparison of the two methods.

In Figure 5, a bar graph is presented in order to compare the enzymatic activity of the seven yeasts using the two spectrophotometric methods, a) rhodamine and b) methyl gallate. The data are expressed as the average of the 10 measurements made along to the kinetics, determining with methyl gallate that the yeasts with greater enzymatic activity are: $D$. hansenii PYC 2968, D. hansenii PYC ISA1510 and C. parapsilosis, while P. kluyvery and I. terricola, had the lowest activity. For the technique with rhodamine, the values obtained are of greater magnitude, indicating that the method has greater stability, noting that D. hansenii PYC ISA1510, P. pastoris and C. parapsilosis, as well as with methyl gallate P. kluyvery and I. terricola, had the least activity.

When comparing the results with previous investigations it showed that for the Lactobacillus plantarum bacteria of strains ATCC14917, CNRZ 184, and 61 D, tannase activities of $0.0057 \pm 0.0002,0.0008 \pm 0.0001,<0.0001 \mathrm{U} \mathrm{mL}^{-1}$ respectively, were reported (Nishitani \& Osawa, 2003); for fungal species such as the Aspergillus strain Aa20 they have been reported from 0.62 to $1.30 \mathrm{U} \mathrm{mL}^{-1}$. The strain Aspergillus sp. GM4 presented enzymatic activity values of $0.13 \pm 0.04$ to $1.44 \pm 0.43 \mathrm{U}$ (mg of protein) ${ }^{-1}$, (Souza et al., 2015). Shi et al. (2005), found tannase activity in the strain C. uilis with values of $32 \mathrm{U} \mathrm{cm}^{-3}$ with 9 days of fermentation. Zhong et al. (2004) cloned and expressed the tannase gene from $A$. oryzae in the yeast $P$. Pastoris, obtaining quantities of $7000 \mathrm{U} \mathrm{L}^{-1}$ of extracellular tannase with $96 \mathrm{~h}$ of fermentation. The activity in the aforementioned bacteria is lower than that determined during this investigation, the values obtained in the fermentations with Aspergillus strain Aa20 and Aspergillus sp. GM4, are similar to those obtained with $P$. pastoris and D. hansenii ISA 1510 and the values obtained in C. utilis with 9 days of fermentation making an extrapolation of the data could reach these values by increasing the time of processes.

According to the research conducted by Beverini \& Metche (1990), they determined that the activity of the enzyme tannase is carried out in two ways: depolymerization and esterification. In the first case, it acts on the ester bond between glucose and gallic acid giving as products glucose, gallic acid and some intermediaries. In the second case, it acts on the ester bond of methylated tannic acid, obtaining tannic acid and methanol. The tests with rhodamine that detects the presence of gallic acid and the constant presence of glucose in the fermentation media determined by DNS, indicate that the enzyme tannase produced by the yeasts is depolymerised.

The generation of glucose and gallic acid by means of hydrolysis was the basis for the determination of the enzymatic 
activity. The first method with rhodamine reacted with the gallic acid present in the medium, forming a chromogen with the rhodamine and being stable in a alkaline medium only at the $\mathrm{KOH}$ concentration that marks the technique, since increasing the concentration self-oxidizes the gallate. The chromogen is stable after its formation for at least 20 minutes at 30 degrees, regardless of the concentration of gallic acid, (Sharma et al., 2000). The second method detects the gallic acid product of the rupture of the bond between the acid molecule and the methyl radical, which make up the methyl gallate that acts as a substrate to be hydrolyzed by the tannase. The later released gallic acid is oxidized to give an easily degradable green to brown colour being stable for a maximum of 1 minute. In addition, the amount of enzyme present in the medium may not be sufficient to hydrolyse the tannic acid molecule and the substrate provided by the technique, making it difficult to differentiate which gallic acid is being measured. Based on this, it is determined that the most suitable tannase detection method for this investigation is the rhodamine technique, for the stability of the formed complex and for the best precision of the obtained results.

\section{Conclusion}

The seven non-conventional yeasts evaluated present enzymatic activity of tannase, with indications of being inducible and extracellular, empathising that for their determination it was not required to break the cellular membrane and there was only enzymatic activity with the presence of tannic acid and zero activities in the control medium or those with $0 \%$. Of the non-conventional yeasts, D. hansenii ISA1510 and P. pastoris stand out.

\section{Acknowledgements}

We thank the partial donations to the investigation "Evaluación de la actividad enzimática de levaduras no-convencionales para la producción de ácido elágico", from the grant Convocatoria de Apoyo a Proyectos de Investigación Científica, Aplicada, Desarrollo Tecnológico e Innovación 2017-2, Tecnológico Nacional de México (6268.17-P).

\section{References}

Aguilar, C. N., Augur, C., Favela-Torres, E., \& Viniegra-González, G. (2001a). Production of tannase by Aspergillus niger Aa-20 in submerged and solid-state fermentation: influence of glucose and tannic acid. Journal of Industrial Microbiology \& Biotechnology, 26(5), 296-302. http://dx.doi.org/10.1038/sj.jim.7000132. PMid:11494106.

Aguilar, C. N., Augur, C., Favela-Torres, E., \& Vinegra-González, G. (2001b). Induction and repression patterns of fungal tannase in solid state and submerged cultures. Process Biochemistry, 36(6), 565-570. http://dx.doi.org/10.1016/S0032-9592(00)00251-X.

Albertse, E. H. (2002). Cloning, expresion and caracterization of Tannase from Aspergillus species (Tesis magistral). Faculty of Natural and Agricultural Sciences Department of Microbiology and Biochemistry. University of the Free State Bloemfontein, South Africa. pp. 8-9.

Aoki, K., Shinke, R., \& Nishira, H. (1976). Purification and some properties of yeast tannase. Agricultural and Biological Chemistry, 40, 79-85.
Barthomeuf, C., Régerat, F., \& Pourrat, H. (1994). Production, purification and characterization of a tannase from Aspergillus niger LCF 8. Journal of Fermentation and Bioengineering, 77(3), 320-323. http:// dx.doi.org/10.1016/0922-338X(94)90242-9.

Beverini, M., \& Metche, M. (1990). Identification, purification, physiochemical properties of tannase from Aspergillus oryzae. Sciences des Aliments, 10, 807-816.

Bradford, M. M. (1976). A rapid and sensitive method for the quantitation of microgram quantities of protein utilizing the principle of proteindye binding. Analytical Biochemistry, 72(1-2), 248-254. http://dx.doi. org/10.1016/0003-2697(76)90527-3. PMid:942051.

Chatterjee, R., Dutta, A., Banerjee, R., \& Bhattacharyya, B. C. (1996). Production of tannase by solid-state fermentation. Biotechnology and Bioprocess Engineering, 14(3), 159-162. http://dx.doi.org/10.1007/ BF00369434.

Doi, S., Shinmyo, A., Enatsu, T., \& Terui, G. (1973). Growth-associated production of tannase by a strain of Aspergillus oryzae. Journal of Fermentation Technology, 51, 768-774.

González-Hernández, J. C., Alcántar-Covarrubias, M. A., \& CortésRojo, C. (2015). Producción de trehalosa a partir de levaduras noconvencionales. Revista Mexicana de Ingeniería Química, 14, 11-23.

Lekha, P. K., \& Lonsane, B. K. (1994). Comparative titres, location and properties of tannin acyl hydrolase produced by Aspergillus niger PKL 104 in solid state, liquid surface and sumerged fermentation. Process Biochemistry, 29(6), 497-503. http://dx.doi.org/10.1016/00329592(94)85019-4.

Miller, G. L. (1959). Use of dinitrosalicylic acid reagent for determination of reducing sugar. Analytical Chemistry, 31(3), 426-428. http://dx.doi. org/10.1021/ac60147a030.

Nishitani, Y., \& Osawa, R. (2003). A novel colorimetric method to quantify tannase activity of viable bacteria. Journal of Microbiological Methods, 54(2), 281-284. http://dx.doi.org/10.1016/S0167-7012(03)00063-0. PMid:12782384.

Ramírez-Coronel, M. A., Viniegra-González, G., Darvill, A., \& Augur, C. (2003). A novel tannase from Aspergillus niger with $\beta$-glucosidase activity. Microbiology, 149(Pt 10), 2941-2946. http://dx.doi.org/10.1099/ mic.0.26346-0. PMid:14523126.

Sharma, S., Bhat, T. K., \& Dawra, R. K. (2000). Spectrophotometric method for assay of tannase using rhodamine. Analytical Biochemistry, 279(1), 85-89. http://dx.doi.org/10.1006/abio.1999.4405. PMid:10683234.

Shi, B., He, Q., Yao, K., Huang, W., \& Li, Q. (2005). Production of ellagic acid from degradation of valonea tannins by Aspergillus niger and Candida utilis. Journal of Chemical Technology and Biotechnology, 80(10), 1154-1159. http://dx.doi.org/10.1002/jctb.1302.

Souza, P. N., Maia, N. D. C., Guimarães, L. H. S., Resende, M. L. V., \& Cardoso, P. G. (2015). Optimization of culture conditions for tannase production by Aspergillus sp. gm4 in solid state fermentation. Acta Scientiarum. Biological Sciences, 37(1), 23. http://dx.doi.org/10.4025/ actascibiolsci.v37i1.22731.

Vázquez-Flores, A., Álvarez-Parrilla, E., López-Díaz, J., \& Wall-Medrano, A. (2012). Hydrolyzable and condensed tannins: chemistry, advantages and disadvantages of their intake. Tecnociencia Chihuahua, 6, 84-94.

Zhong, X., Peng, L., Zheng, S., Sun, Z., Ren, Y., Dong, M., \& Xu, A. (2004). Secretion, purification, and characterization of a recombinant Aspergillus oryzae tannase in Pichia pastoris. Protein Expression and Purification, 36(2), 165-169. http://dx.doi.org/10.1016/j. pep.2004.04.016. PMid:15249037. 